\title{
The effect of Oxalis corniculata extract against the behavioral changes induced by 1-methyl- 4-phenyl-1,2,3,6-tetrahydropyridine (MPTP) in mice
}

\author{
K. Aruna ${ }^{1}$, P. Devi Raja Rajeswari ${ }^{1 *}$, S. Raja Sankar ${ }^{2}$ \\ ${ }^{1}$ Bharath University, Chennai \& ${ }^{1}$ Dept. of Anatomy, Rajas Dental College, Tirunelveli, India. \\ ${ }^{2}$ Velemmal Medical College Hospital \& Research Institute, Madurai, India.
}

\begin{tabular}{l} 
ARTICLE INFO \\
\hline Article history: \\
Received on: $31 / 10 / 2016$ \\
Accepted on: 11/12/2016 \\
Available online: $30 / 03 / 2017$ \\
\hline Key words: \\
Behaviour, MPTP, Oxalis \\
corniculata, Parkinson's \\
disease.
\end{tabular}

\begin{abstract}
Parkinson's disease (PD) is a neurodegenerative disorder characterized by the development of rigidity, resting tremors and postural instability. Recently, the focus of PD's treatment has shifted towards herbal medicines. The aim of the study was to evaluate neuroprotective effect of alcoholic extract of Oxalis corniculata (Oxalidaceae), via the analysis of behavioral features in MPTP (1-methyl,4- phenyl-1,2,3,6-tetra hydro pyridine) mouse model. Behavioral studies were performed by the actophotometer, elevated plus maze, rotarod, hole board, step down and step through tests. Treatment with $O$. corniculata reversed the alterations in locomotor and muscle coordination in MPTP induced Parkinsonic mouse. The results achieved in this study reveal that different doses of $O$. corniculata increased memory retention and retrieval significantly. Memory retention and retrieval enhancement by $O$. corniculata extract could be due to the presence of antioxidants such as flavonoids, coumarins, tocopherols and phenolic acids and their power in scavenge reactive oxygen species.
\end{abstract}

\section{INTRODUCTION}

Parkinson's disease (PD) is an age-related progressive neurodegenerative disease, which is characterized by resting tremors, rigidity, postural abnormalities, particularly stooped posture, and difficulty or failure to execute willed movements, i.e. bradykinesia, akinesia and festinating gait (Tillerson et al., 2003; Oida et al., 2006). Parkinson's disease was recorded in ancient India. It was called as Kampavatha. Many traditional medicinal plants were used for the healing of many diseases including stress, insomnia, anxiety, arthritis and other disorders related to the central nervous system (CNS) such as PD and Alzheimer's disease. The extracts of herbal medicine have been reported for its defensive effects against neurotoxicity in vitro and in vivo models of Parkinson's disease (Sankar et al., 2007;

\footnotetext{
* Corresponding Author

P. Devi Raja Rajeswari, Ph.D. Scholar, Bharath University, Chennai \& \$ Dept. of Anatomy, Rajas Dental College, Tirunelveli, India.

E-mail:saran_gan @ rediffmail.com
}

Babita et al., 2014; Rajasankar et al., 2009; Srinivasagam Raja Sankar et al., 2007). MPTP (1-methyl -4 -phenyl-1, 2, 3, 6tetrahydropyridine) is a potent neurotoxin which results in selective degeneration of dopaminergic neurons projecting from substantia nigra pars compacta ( $\mathrm{SNpc}$ ) into striatum and mimics PD-like symptoms in experimental models (Smeyne and JacksonLewis, 2005). Oxalis corniculata is a medicinally important plant indigenous to tropical and subtropical regions of the world. Oxalis corniculata exhibits wound healing activity (Taranalli et al., 2004), cardio relaxant activity (Achola et al., 1995), nematocidal activity (Silamar and Leandro, 2005), anticancer activity (Kathiriya et al., 2010), antimicrobial activity (Raghvendra et al., 2006), antifungal activity (Iqbal et al., 2001), antiamoebic activity (Manna et al., 2010), antiimplantation and abortifacient (Sharangouda and Patil, 2007), allelopathic activity (Itani et al., 1999), antioxidant activity (Reddy et al., 2010) and steroidogenic activity (Seraphim and Sinha, 2010). Recently, O. corniculata was also reported to exhibit potent anxiolytic potential, nephroprotective, anti-stress and memory enhancing properties (Sai Sampath et al., 2011). 
But so far their protective effect in neurodegenerative disorders such as PD has not been studied. In the present study, the protective effect of $O$. corniculata against MPTP-induced behavioral deficits in mouse model of PD was investigated.

\section{EXPERIMENTAL}

\section{Chemicals and reagents}

MPTP hydrochloride was purchased from Sigma Chemical Co. Analytical grade chemicals were used for the experimental analysis. Stock solutions of all chemicals were prepared in double distilled water and the dilutions were made fresh on the day of the experiment.

\section{Plant extract}

The medicinal plant Oxalis corniculata was collected from Tirunelveli District, Tamil Nadu, India. Mature and healthy plants were collected naturally from different locations after the rainy season (February, March and April). The collected specimens were identified referring to the Flora of Presidency of Madras (Gamble, 1915-1921) and Flora of Tamil Nadu Carnatic (Mathew, 1983 -1988). The collected plant materials were shadedried at room temperature $\left(20-25^{\circ} \mathrm{C}\right)$ for a period of 3 weeks to 8 weeks. For extraction, the completely dried materials were made into coarse powder by mechanical grinder. The powder was passed through a 40-mesh sieve, to get a uniform particle size. A weighed quantity of powder was subjected to continuous hot percolation in soxhlet apparatus with ethanol at $65-70^{\circ} \mathrm{C}$. All the solvent had been removed by evaporating under reduced pressure using rotaflash evaporator. The concentration of the extract was $12 \%$ w/w. when compared to the dried starting material. It was then stored at $-20^{\circ} \mathrm{C}$ until required.

\section{Animals}

C57 Black male mice, weighing 25-30 gm were used. All animals were obtained from the Animal house, KMCH College of Pharmacy, Coimbatore, Tamil Nadu. They were allowed food and water ad libitum upto the experimentation period. Prior to use, the mice were housed in polypropylene cages in group of six to eight animals under natural light-dark cycle. Each animal was used only once under standard laboratory conditions. All the observations were made at room temperature in a noiseless diffusely illuminated room and were made between 9.00 to $17.00 \mathrm{~h}$ in the experimental room. All the experimental protocols were approved by Institutional Animals Ethics Committee (IAEC) as per provisions of Committee for the Purpose of Control and Supervision of Experimental Animals (CPCSEA) (KMCRET/PhD/ /2014-15), New Delhi, India.

\section{Experimental protocol}

The following experimental procedure was followed to evaluate the locomotor behavioral effect of $O$. carniculata $(\mathrm{OC})$ on MPTP induced mice. 1-methyl-4-phenyl-1, 2, 3, 6tetrahydropyridine (MPTP): $15 \mathrm{mg} / \mathrm{kg}$ of MPTP as a neurotoxin i.p. twice, $4 \mathrm{~h}$ apart in vivo and $20 \mu \mathrm{M}$ in vitro. MPTP was purchased from Sigma, India. MPTP was dissolved in $0.9 \%$ saline and administered i.p. Intraperitonial injection of MPTP was given to Groups II,III, IV and V. Oral dosage of Carbidopa + Levadopa (Standard drug for Parkinson's disease treatment) was given to Groups III.

The animals were divided into six groups, each consisting of six mice.

1. Group I served as vehicle control (Distilled water)

2. Group II received MPTP $(20 \mathrm{mg} / \mathrm{kg}$, i.p) (SigmaAldrich, Bangalore, India) four consecutive days,

3. Group III received MPTP + carbidopa + levodopa $(100 \mathrm{mg} / \mathrm{kg}$, p.o)

4. Group IV received MPTP + crude extract (250 $\mathrm{mg} / \mathrm{kg}, \mathrm{p} . \mathrm{o})$

5. Group V received MPTP + crude extract (500 $\mathrm{mg} / \mathrm{kg}, \mathrm{p} . \mathrm{o})$

6. Group VI received only crude extract (500 mg/kg, p.o)

\section{Experimental analysis}

The actions of plant extract on spontaneous locomotor activity were measured automatically using Actophotometer (Medicraft photoactometer, model No: 600-40, S. No: PA-0149, India) (Rabbani et al., 1995). Motor Co-ordination test was conducted using a Rota Rod apparatus (Inco Ambala, India) (Kulkarni, 1987). The elevated plus maze was carried out as described by Pellow et al. (1985). Hole board test was done by the standard procedure (Nade and Yadav, 2008). Step down inhibitory avoidance was measured by the procedure given by Dhingra et al. 2006. Passive avoidance task (Step Through Latency - STL) was studied by the Tamburella's procedure (Tamburella et al., 2012).

\section{Statistical analysis}

Values are expressed as the mean \pm S.D. Statistical implication (p) calculated by one way ANOVA followed by Dunnett's. ns- not significant ${ }^{*} P<0.001{ }^{* *} P<0.01 \quad * * * P<0.05$ calculated by comparing treated group with control group.

\section{RESULTS}

\section{Actophotometer}

The animals induced with MPTP shows sluggish movement in the Actophotometer. But, when the animals are treated with MPTP and $500 \mathrm{mg}$ of Oxalis extract the movements are increased. When the animals are treated only with the alcoholic extract of Oxalis show significant increase in movement $(\mathrm{p}<0.001)$ when compared to MPTP + standard treated group as shown in Table 1. MPTP $+500 \mathrm{mg} / \mathrm{kg}$ Oxalis extract shows improvement in movement of the animal when compared with the movement of MPTP induced groups. This may be due to the CNS stimulant property of the drug. 
Table 1: Effects of $O$. corniculata ethanol extract in the Actophotometer test and Elevated plus maze test.

\begin{tabular}{cccc} 
Group & Actophotometer (A.F) & $\begin{array}{c}\text { Elevated plus maze (A.F) open } \\
\text { entries }\end{array}$ & $\begin{array}{c}\text { Elevated plus maze (A.F) } \\
\text { Dark entries }\end{array}$ \\
\hline Control & $79.60 \pm 12.012$ & $12.00 \pm 10.040$ & $157.00 \pm 20.861$ \\
Only MPTP & $48.80 \pm 29.201$ & $2.17 \pm 1.169$ & $140.67 \pm 15.175$ \\
MPTP + Standard & $63.00 \pm 9.772$ & $8.17 \pm 7.167$ & $156.50 \pm 12.046$ \\
MPTP + Oxalis 250mg/kg & $56.20 \pm 14.516$ & $5.33 \pm 5.279$ & $142.83 \pm 13.393$ \\
MPTP + Oxalis 500mg/kg & $57.80 \pm 20.813$ & $4.83 \pm 8.035$ & $146.00 \pm 14.642$ \\
Only Oxalis 500mg/kg & $67.33 \pm 14.306$ & $5.80 \pm 3.033$ & $158.50 \pm 8.871$ \\
\hline
\end{tabular}

Table 2: Effects of $O$. corniculata ethanol extract in the Hole Board test and Rota rod test.

\begin{tabular}{ccc}
\hline Group & Hole board (A.F) & Rota rod apparatus (A.F) \\
\hline Control & $16.43 \pm 24.186$ & $133.67 \pm 30.898$ \\
Only MPTP & $7.29 \pm 10.935$ & $40.17 \pm 12.090$ \\
MPTP + Standard & $12.14 \pm 16.466$ & $33.00 \pm 10.119$ \\
MPTP + Oxalis 250mg/kg & $8.71 \pm 3.251$ & $43.00 \pm 13.100$ \\
MPTP + Oxalis 500mg/kg & $13.50 \pm 4.416$ & $35.33 \pm 16.525$ \\
Only Oxalis 500mg/kg & $14.57 \pm 18.564$ & $36.50 \pm 11.502$ \\
\hline
\end{tabular}

Table 3: Effects of $O$. corniculata ethanol extract in the Step down test and step through test

\begin{tabular}{ccc}
\hline Group & Step down (A.F) & Step through (A.F) \\
\hline Control & $1.50 \pm 0.548$ & $1.67 \pm 0.516$ \\
Only MPTP & $1.17 \pm 0.408$ & $1.17 \pm 0.408$ \\
MPTP + Standard & $1.33 \pm 0.516$ & $1.33 \pm 0.516$ \\
MPTP + Oxalis 250mg/kg & $1.17 \pm 0.408$ & $1.17 \pm 0.408$ \\
MPTP + Oxalis 500mg/kg & $1.33 \pm 0.516$ & $1.33 \pm 0.516$ \\
Only Oxalis 500mg/kg & $1.17 \pm 0.408$ & $1.50 \pm 0.548$ \\
\hline
\end{tabular}

\section{Elevated plus maze}

The entries of C57 mice into dark are the normal character. The control group of mice shows more number of dark entries. The MPTP induced mice shows reduction of number of dark entries. But the group treated with MPTP and $500 \mathrm{mg}$ of Oxalis extract shows increase in dark entries (146.00 \pm 14.642$)$. This proves that the nature of normal activity (i.e. entering into the dark area) of the animals is induced when the extract of Oxalis is administered. The effects of group and maze experience on plusmaze behavior in male mice are summarized in Table 1 .

\section{Hole Board}

In the hole board test, the normal, control group of animals show more number of dips into the hole board as an escaping mechanism. The group induced by MPTP shows less number of dips compared to control group. But, when the animals are treated with Oxalis $500 \mathrm{mg}$ extract, show great improvement and exhibit more number of dips more than that of MPTP + standard groups. The number of head poking after administration of MPTP + Oxalis $500 \mathrm{mg} / \mathrm{kg}$ was comparable with the standard drug carbidopa + levodopa $(100 \mathrm{mg} / \mathrm{kg})$ and the values are significantly higher compared to the control group (Table: 2). Selected plant extract exhibits significant activity as compared to MPTP + standard.

\section{Rota rod apparatus}

A formal test related to beam walking is balancing on a rotating rod, the "rotorod" test. The test consisted of a rotating rod upon which the animal balances. As the animals learn to balance, the rod is turned increasingly faster. The measure of motor skill is the time the animal spends on the rotorod as a function of speed with which the rod rotates (Le Marec et al., 1997).

The capacity of withstanding in the rotarod apparatus is more in the control group. But, when the animals are induced with MPTP, they fall very easily from the rotatod and the time taken for each fall becomes very minimal. The group treated with MPTP and $250 \mathrm{mg}$ of Oxalis extract shows slight improvement. The result from the Rotarod test showed that the extract significantly increased the motor coordination of the tested animals. The data shows that an average the mice treated with 250 and $500 \mathrm{mg} / \mathrm{kg}$ of the ethanolic extract of Oxalis corniculata were able to maintain equilibrium on the rotating rod and stayed on longer without falling (Table: 2) as compare with MPTP + standard.

\section{Step down}

Effect of ethanol extract of Oxalis corniculata on memory was observed using step down model in mice. Almost all the groups show similar results only. There is no much difference between the control group or induced group or treated group with Oxalis. The results obtained for the MPTP $+500 \mathrm{mg} / \mathrm{kg}$ Oxalis treated group can improve the long-term retention of a step-down inhibitory avoidance task in mice (Table: 3 ). MPTP $+500 \mathrm{mg} / \mathrm{kg}$ Oxalis treated and MPTP + Standard drug exhibits similar activity.

\section{Step through}

Step through is a passive avoidance test. It is a simple and rapid test method for memory assessment (Das et al., 2000). In the test-performed animals treated with MPTP exhibited a sharp decline in memory retention and treatment with $O$. corniculata improved the condition and was comparable to control animals. 
On the $7^{\text {th }}$ day MPTP administered mice showed significant difference and remarkable decrease in step through transfer latency (1.17 \pm 0.408$)$, when compared to control $(1.67 \pm 0.516)$ and $O$. corniculata $(500 \mathrm{mg} / \mathrm{kg})$ ethanol extract treated mice $(1.50 \pm 0.548)$ (Table: 3). Group V and Group VI animals were treated with alcoholic extracts of $O$. corniculata shows restoration of locomotion compared to control group at the significant level.

\section{DISCUSSION}

Alcoholic extract of $O$. corniculata was assessed for the neuropharmacological evaluation in MPTP treated mice. Spontaneous motor activity, exploratory behaviour and motor synchronization were decreased in MPTP treated group, it could be due to motor mutilation and muscle relaxant effect. On treatment with alcoholic extract of $O$. corniculata reversed the behavior alterations induced by MPTP on $3^{\text {rd }}$ day, but maximum effect of extract was seen on $6^{\text {th }}$ day of treatment. It might be due to presence of phytoconstituents like L-dopa, polyphenols and flavonoids (Mohanasundari et al., 2006).

Elevated plus maze (EPM) is one of the most important animal behavioral experiments used in evaluation of anxyolitic effect of drugs (Pellow et al., 1985; Pellow and File, 1986). Moreover, it is known that anxiolytic agents increase the frequency of entries and the time spent in open arms of the EPM (Pellow et al., 1985). Administration of $O$. corniculata extract significantly increased $(\mathrm{p}<0.05)$ the percentage of entries and permanence time into open arms, compared with control group. The results of experiment confirmed that on first exposure to the plus maze, male mice exhibit a clear preference for the closed/protected parts of the apparatus. The transfer latency measured and the Oxalis treated mice was drastically shorter than on the first day, indicating the ability of the rats to recall the learned aspect in a lesser period of time. The effects of $O$. corniculata seem to be more potent than MPTP group in comparison to experimental groups. The fear due to height induces anxiety in the animals when placed on the EPM. The ultimate manifestation of anxiety and fear in the animals is exhibited by decrease in the motor activity and preference to remain at safer places. Antianxiety agents are expected to increase the motor activity, which is measured by the time spent by the animal in the open arms. The spontaneous decrease in basal activity score implicates the reduced anxiety recorded using Actophotometer. The antianxiety and antidepressant effects may be due to the flavonoid (Vikas et al., 2012) content present in the alcoholic extract of Oxalis corniculata. Hole board test indicates that head dipping behaviour is sensitive to changes in the emotional state of the animal and suggested that the expression of an anxiolytic state in animals may be reflected by an increase in head poking behaviour (Takeda et al., 1998). O. corniculata extract increased head-dip counts without changing locomotion in the hole-board test. Additionally, $O$. corniculata increased visits numbers to board compared with control group. These results imply that $O$. corniculata has a considerable anxiolytic effect in this paradigm.
The ethanolic extract of $O$. corniculata contains flavanoids, phenolic content as well as terpenoid compounds like $\beta$ sitosterol, caemphesterol, etc, which are probably responsible for the actions (Bajracharya, 1979).

The hole board test is useful for modeling anxiety in animals, in this test an anxiolytic-like state may be reflected by an increase in head -dipping behaviors (Takeda et al., 1998). In the present study, results showed that ethanolic extract $(500 \mathrm{mg} / \mathrm{kg})$ of Oxalis corniculata increased the head dipping corroborating the anxiolytic-like effect previously shown in the light- dark test. The anxiolytic effect of alkaloids (Martinez-Vazquez et al., 2012), flavonoids (Li et al., 2011) and saponins (Wei et al., 2007) has been previously reported and, therefore, suggest that these anxiolytic effects may be due to the above constituents. Most of the anxiolytic agents exert their action by opening of activated GABAchloride channel. It is also reported that many flavonoids were found to be ligands for the GABA-A receptors in the central nervous system (Mohammed, 2014). The above results reveals that the ethanolic extract of Oxalis corniculata have satisfactory anxiolytic effect.

Rota rod test a classical animal behaviour test used to evaluate peripheral neuromuscular blockade and the motor coordination (Amos et al., 2001), a deficit in motor coordination would very likely affect performance in the behavioral tests. Rota rod test, the difference in the fall of time from the rotating rod between the vehicle and extract treated groups were taken as an index of muscle relaxation. Plant extract showed significant increase in the locomotory score and fall of time of the mice from the rotating rod.

The investigation of the pharmacology of memory between the 1960s and 1980s involved the analysis of the modulation of memory, namely the drugs, hormones, neurotransmitters and neuromodulators that affect memory consolidation. The studies showed that modulatory substances could influence the basic mechanisms of memory processing (Bär et al., 1982). Memory improving drugs generally work by altering the neurotransmitters in the brain that are involved in the initial learning of a memory or its subsequent reinforcement (Ingole et al., 2008). The present study investigated the effect of Oxalis corniculata on memory retention and retrieval using the passive avoidance step down model. The results achieved in this study reveals that different doses of $O$. corniculata improved memory retention and retrieval significantly $(\mathrm{p}<0.05)$. Previous studies on memory retention and retrieval indicated that plants contain large amounts of antioxidants which improve memory, for example, various species of Ocimum (Dokania et al., 2011; Sarahroodi et al., 2012), Saffron (Abe and Saito, 2000), Ginkgo biloba (Rigney et al, 1999), green tea (Wu et al, 2012), Magnolia officinalis (Lee et al, 2012), Curcumin (Bishnoi et al, 2008) and Anacyclus pyrethrwn (Sujith et al, 2012). Memory retention and retrieval enhancement by $O$. corniculata extract could be due to the presence of antioxidants such as flavonoids, cinnamic acid derivatives, coumarins, tocopherols and phenolic acids and their power in scavenge reactive oxygen species. 
In view of the above results, it concludes the $O$. corniculata extract in different experimental series enhanced learning and memory performance in mice, probably a result of reduces of oxidative stress by antioxidant defense mechanisms. This effect of $O$. corniculata concerned modulation of cholinergic neurotransmission, and that it may be utilize as a potential agent in treatment of neurodegenerative diseases such as Alzheimer's disease, Parkinsonism and other type of dementia and memory deterioration. There were some significant improvements in motor performance, coordination and spontaneous activity with no significant change in stride length or grooming tendencies. It can be interpreted that these parameters are correlated with dopaminergic markers in the striatum (Tillerson et al., 2002; Tillerson and Miller, 2003).

\section{CONCLUSION}

The findings of this study indicate that OC extract attenuates MPTP-induced cognitive and behavioural impairments in mouse model of PD. Regulation of antioxidant defense mechanisms by OC may partly be responsible for its neuroprotective effect in MPTP-induced PD mice.

\section{ACKNOWLEDGEMENT}

The authors are grateful to Dr. A. Saravana Ganthi, H.O.D in the Department of Botany, Rani Anna Govt. College for women, Tirunelveli, Tamil Nadu for his valuable support.

Conflict of Interests: There are no conflicts of interest.

\section{REFERENCES}

Abe K, Saito H. Effects of saffron extract and its constituent crocin on learning behavior and long term potentiation. Phytother. Res. 2000;14: 149-152.

Achola KJ, Mwangi JW, Munenge RW. Pharmacological activity of Oxalis Corniculata. Pharmaceutical Biology. 1995; 33: 247249.

Amos S, Adzu B, Binda L, Wambebe C, Gamaniel K. Neuropharmacological effect of the aqueous extract of Sphaeranthuss enegalensis in mice. J. Ethnopharmacol. 2001;78 (1): 33-37.

Babita S, Abbas AM, Shivani P. Bacopa monnieri promoter of Anioxidant property in MPTP-Induced Parkinson's Disease. International J. Scientific and Innovative Research. 2014; 2 (2): 1-7.

Bajracharya MB. Ayurvedic Medicinal Plants and General Treatment. Kathmandu: Jore Ganesh Press. 1979.

Bär PR, Jolles J, Oestreicher AB, Zwiers H, Someren H, Schotman P, Gispen, WH. Phosphorylation of synaptic membrane constituents: target of modulation by behaviourally active neuroptides. In: Ajmone-Marsan, C.; Matthies, H. (Eds.). Neuronal plasticity and memory formation. New York, Raven Press. 1982;123-136.

Bishnoi M, Chopra K, Kulkarni SK. Protective effect of Curcumin, the active principle of turmeric (Curcuma longa) in haloperidol-induced orofacial dyskinesia and associated behavioural, biochemical and neurochemical changes in rat brain. Pharmacol. Biochem. Behav. 2008; 88: 511-522.

Das A, Kapoor K, Sayeeepriyadarshini AT, Dikshit M, Pallit G, Nath C. Immobilization stress- induced changes in brain acetylcholinesterase activity and cognitive function in mice. Pharmacol. Res. 2000; 42: 213-217.
Dhingra D, Parle M. and Kulkarni SK. " $\beta$ : Alanine protects mice from memory deficits induced by ageing, scopolamine, diazepam and ethanol". Indian J. Pharma. Sci. 2006;68: 216-221.

Dokania M, Kishore K, Sharma PK. Effect of Ocimum sanctum extract on sodium nitrite-induced experimental amnesia in mice. Thai J. Pharm. Sci. 2011;35: 123-130.

Gamble JS. Oxlidaceae In: Flora of the Presidency of Madras, Bishen Singh Mahandra Pal Singh Dehra Dun 1915 - 1921.

Ingole SR, Rajput SK, Sharma SS. Cognition Enhancers: Current Strategies and Future Perspectives. CRIPS. 2008;42-48.

Iqbal MC, Meiyalaghan S, Wijesekara KB, Abeyrante KP. Antifungal activity from water extracts of some common weeds. Pakistan J. Biological Science. 2001; 4: 843-845.

Itani T, Fujita T, Tamaki M, Kuroyanagi M, Fujii Y. Allelopathic activity and Oxalate content in oxalate-rich plants. J. Weed Science and Technology. 1999; 44: 316-323.

Kathiriya A, Das K, Kumar EP, Mathai KB. Evaluation of antitumor and antioxidant activity of oxalis corniculata Linn. against ehrlich ascites carcinoma on mice. Iranian J. cancer prevention. 2010;4: 157-165.

Kulkarni SK. "Hand book of experimental pharmacology". Vallabh Prakashan, New Delhi. 1987; 122.

Le Marec N, Stelz T, Delhaye-Bouchaud N, Mariani J, Caston J. Effect of cerebellar granule cell depletion on learning of the equilibrium behaviour: study in postnatally $\mathrm{X}$-irradiated rats. European $\mathrm{J}$. Neuroscience. 1997; 9: 2472-2478.

Lee YJ, Choi DY, Han SB, Kim YH, Kim KH. Inhibitory effect of ethanol extract of Magnolia officinalis on memory impairment and amyloidogenesis in a transgenic mouse model of Alzheimer's disease via regulating secretase activity. Phytother. Res. 2012;26: 1884-1892.

Li H, Zhou P, Yang Q, Shen Y, Deng J. Comparative studies on anxiolytic activities and flavonoid compositions of Passiflora edulis 'edulis' and Passiflora edulis 'flavicarpa'. J. Ethnopharmacol. 2011; 133: 1085-1090.

Manna D, Dutta P K, Achari B, Lohia AA. Novel GalactoGlycerolipid from Oxalis corniculata Kills Entamoeba histolytica and Giardia lamblia. Antimicrobial agents and chemotherapy. 2010; 54: $4825-$ 4832 .

Martínez-Vázquez M, Estrada-Reyes R, Araujo Escalona AG, Ledesma Velázquez I, Martínez-Mota L. Antidepressant-like effects of an alkaloid extract of the aerial parts of Annona cherimolia in mice. J. Ethnopharmacol. 2012; 139: 164-170.

Matthew KM. The Flora of Tamil Nadu Carnatic Vol I, The Rapinat Herbarium, Tiruchirappali, India 1983 - 1988

Mohammed SP, Latheef N, Sri Ganeshan P. Evaluation of Anxiolytic Activity of Ixora coccinea Linn. Ethanolic Extract in Swiss Albino Mice. Clin Exp. Pharmacol. 2014;4: 146.

Mohanasundari M, Sethupathy S, Sabesan M. The effect of Hypericum perforatum extract against the neurochemical and behavioural changes induced by 1-methyl-4-phenyl-1,2,3,6tetrahydropyridine (MPTP) in mice. Indian J. Pharmacology. 2006; 38 (4): 266-270

Nade VS, Yadav VA. "Anti-dopaminergic effect of the methanolic extract of Morus alba L. leaves". Indian J. Pharmacol. 2008; 40 (5): $221-226$

Oida Y, Kitaichi K, Nakayama H, Ito Y, Fujimoto Y, Shimazawa M, Nagai H, Hara H. Rifampicin attenuates the MPTP induced neurotoxicity in mouse brain. Brain Res. 2006; 1082 : 196-204.

Pellow S, Chopin P, Briley M, File SE. "Validation of open: closed arm entries in an elevated plus-maze: a novel test of anxiety in the rat". J. Neurosci. 1985; 14: 149-167.

Pellow S, File S. Anxiolytic and anxiogenic drug effects on exploratory activity in an elevated plus maze: a novel test of anxiety in the rat. Pharmacol. Biochem. Behav. 1986; 24: 526-530.

Rabbani M, Wright EJ, Little HJ. Tolerance to competitive NMDA antagonists, but no cross tolerance with barbiturates. Pharmacol Biochem Behav. 1995;50:9-15. 
Raghvendra MP, Satish S, Raveesha KA. Phytochemical analysis and antibacterial activity of Oxalis corniculata, a known medicinal plant. My Science. 2006; 1: 72-78.

Raja Sankar S, Manivasagam T, Sankar V, Prakash S, Muthusamy R, Krishnamurti A, Surendran S. Withania somnifera root extract improves catecholamines and physiological abnormalities seen in a Parkinson's disease model mouse. J. Ethnopharmacol. 2009;125 (3): 36973.

Reddy KY, Kumar SA, Lakshmi SM, Angothu S. Antioxidant Properties of Methanolic extract of Oxalis corniculata. International J. Phytopharmacology. 2010; 1: 43-46.

Rigney U, Kimber S, Hindmarch I. The effects of acute doses of standardized Ginkgo biloba extract on memory and psychomotor performance in volunteers. Phytother. Res. 1999;13: 408-415.

Sai Sampath. T, Santosh.P, Mangala Lahkar, Ajaygodwin.P, Pavan Kumar. S Lingesh. A. Anxiolytic effect of ethanolic extract of Oxalis corniculata L. in mice Int. J. Pharma and Bio Sciences 2011;2(3): $285-290$.

Sankar S, Manivasagam T, Krishnamurti A, Ramanathan, M. The neuroprotective effect of Withania somnifera root extract in MPTPintoxicated mice: An analysis of behavioral and biochemical variables Cell Mol. Biol. Lett. 2007;12 (4): 473-481.

Sarahroodi S, Esmaeili S, Mikaeili P, Hemmati Z, Saberi Y. The effect of green Ocimum basilicum hydroalcoholic extract on memory retention and retrieval of memory in mice. Ancient Life Sci. 2012;31: 172 176.

Seraphim ER, Sinha MP. Impact of Phytoestrogens on endocrine glands of albino rats, adrenal. The Bioscan. 2010; 5 (1): 63-66.

Sharangouda K, Patil SB. Oxalis corniculata (whole plant) extracts exhibit estrogenic activities in wistar strain albino rats. The Bioscan.2006; 1: 63-67.

Silamar F, Leandro GF. Use of antagonistic plants and natural products. In: Chen X, Chen Y, Dickson DW. Nematology advance and perspectives. International, UK. 2005;2 (33): 931-977.

Smeyne RJ, Jackson-Lewis V. The MPTP model of Parkinson's disease Molecular Brain Research. 2005;134: 57 - 66.

Srinivasagam RS, Thamilarasan M, Arumugam K, Manickam R. The neuroprotective effect of Withania somnifera root extract in MPTP-intoxicated mice: An analysis of behavioral and biochemical variables Cellular and Molecular Biology Letters. 2007;12 (4): 473-481.

Sujith K, Darwin CR, Safhish, Suba V. Memory enhancing activity of Anacyclus pyrethrum in albino Wistar rats. Asian Pacific J. Trop. Dis. 2012;2: 307-311.
Takeda H, Tsuji M, Matsumiya T. Changes in head-dipping behavior in the hole-board test reflect the anxiogenic and/or anxiolytic state in mice. Eur. J. Pharmaco. 1998; 13 (50): 21-29.

Tamburella A, Micale V, Mazzola C, Salomone S, Drago F. The selective norepinephrine reuptake inhibitor atomoxetine counteracts behavioral impairments in trimethyltin-intoxicated rats. Eur $J$ Pharmacol.2012; 683(1-3):148-154.

Taranalli AD, Tipare SV, Kumar S. Wound healing activity of Oxalis corniculata whole plant extract in rats. Indian J. Pharmaceutical Sciences. 2004; 66 (4): 444-446.

Tillerson JL, Caudle WM, Reveron ME, Miller GW. Detection of behavioral impairments correlated to neurochemical deficits in mice treated with moderate doses of 1-methyl-4-phenyl-1,2,3,6tetrahydropyridine. Exp. Neurol. 2002;178: 80-90.

Tillerson JL, Miller GW. Grid performance test to measure behavioral impairment in the MPTP-treated-mouse model of parkinsonism. J. Neurosci. Methods 2003;123: 189-200.

Vikas G, Parveen B, Pawan K, Richa S. Anxiolytic and antidepressant activities of different extracts from Citrus paradisi Duncan. Asian J. Pharmaceutical and Clinical Research. 2012; 98-99.

Wei XY, Yang JY, Wang J, Wu CF. Anxiolytic effect of saponins from Panax quinquefolium in mice. J. Ethnopharmacol. 2007;111: 613-618

Wu KJ, Hsieh MT, Wu CR, Wood WG, Chen YF. Green tea extract ameliorates learning and memory deficits in ischemic rats via its active component polyphenol epigallocatechin-3-gallate by modulation of oxidative stress and neuro inflammation. Evid. Based Complement. Alternat. Med. 2012;12(1): 89 -91.

\section{How to cite this article:}

Aruna K, Rajeswari PDR, Sankar SR. The effect of Oxalis corniculata extract against the behavioural changes induced by 1methyl-4-phenyl-1,2,3,6-tetrahydropyridine (MPTP) in mice. J App Pharm Sci, 2017; 7 (03): 148-153. 